IRSTI $28.17 .23 ; 29.15 .35$

\author{
${ }^{1}$ F.F. Komarov, ${ }^{2}$ A.I. Kupchishin, ${ }^{3 *}$ T.A.Shmygaleva, \\ ${ }^{3}$ S.T. Janybekova, ${ }^{4}$ A.A. Kuatbayeva, ${ }^{3}$ A.B. Bekaydar \\ ${ }^{1}$ Belarusian State University, Minsk, Belarus \\ ${ }^{2}$ Kazakh national pedagogical University after named Abay, Almaty, Kazakhstan \\ ${ }^{3}$ al-Farabi Kazakh National University, Almaty, Kazakhstan \\ ${ }^{4}$ Sh. Ualikhanov Kokshetau State University, Kokshetau, Kazakhstan \\ *e-mail: shmyg1953@mail.ru

\section{Computer modeling of processes of radiation defection formation in aluminum irradiated by ions}

\begin{abstract}
The article considers the process of interaction of ions with aluminum and the formation of the radiation defects. The selection of an approximate expression for the interaction cross section is found and the approximation coefficients are found. Algorithms of calculation of a cascade probability function, range of the primary beaten-out atoms, concentration of radiation defects are given. Calculations of cascade probability functions depending on number of interactions and a depth of penetration of particles, ranges of the primary beaten-out atoms (PKA), concentration of radiation defects are made. Regularities of behavior and finding of area of result when calculating cascade probability functions depending on number of interactions and a depth of penetration of particles, concentration of radiation defects for the aluminum irradiated with ions are received. It is necessary to consider various factors: types of flying particles (charged and uncharged, light and Heavy), a real "physical" picture; i.e. processes occurring at interaction of particles with a substance.
\end{abstract}

Key words: ion, aluminium, approximation, algorithm, calculation, cascade-probabilistic function, the concentration of radiation defects.

\section{Introduction}

Modern development of science and technology requires the creation of fundamentally new materials that meet the requirements of various fields of energy. These materials should possess qualitatively new physical and chemical properties that assumes a detail study of structure of materials under the influence of the ionizing radiation and obtaining the defect information in structure of materials. A consequence of the action of ionizing radiation is a sharp change in their properties. Predicting the behavior of materials under harsh operating conditions requires the creation of quantitative models explaining radiation defect formation [1-8].

It is necessary to consider various factors: types of flying particles (charged and uncharged, light and Heavy), a real "physical" picture; i.e. processes occurring at interaction of particles with a substance. Aluminium is taken in the work.
Aluminium and its alloys are increasingly used in shipbuilding Aluminum alloys are used for manufacturing ship hulls, deck superstructures, communication and various types of ship equipment. The main characteristics of aluminum and its alloys, revealing the expediency of their application in railway transport, high specific strength, small force of inertia, corrosion resistance. The introduction of aluminum alloys in the manufacture of welded tanks increases their durability in the transportation of a number of products of the chemical and petrochemical industry. One of the main requirements for materials used in road transport is low weight and relatively high strength. The corrosion resistance and good decorative surface of the material are also taken into consideration. The high specific strength of aluminum alloys increases the carrying capacity and reduces the operating costs of mobile transport. High corrosion resistance of the material extends 
service life, expands the range of transported goods, including liquids and gases with high aggressive concentration.

The work is performed within the framework of a cascade-probabilistic method, the essence of which is to obtain and further use of cascadeprobability functions $(\mathrm{CPF})$ having the sense of the probability of reaching a particle of a certain depth $h$ after the $\mathrm{n}$-th number of collisions [9-11].

\section{Main results}

The cascade probability function for ions has the following form [11]:

$$
\psi_{n}\left(h^{\prime}, h, E_{0}\right)=\frac{1}{n ! \lambda_{0}^{n}}\left(\frac{E_{0}-k h^{\prime}}{E_{0}-k h}\right)^{-l} \exp \left(\frac{h-h^{\prime}}{\lambda_{0}}\right) *\left[\frac{\ln \left(\frac{E_{0}-k h^{\prime}}{E_{0}-k h}\right)}{a k}-\left(h-h^{\prime}\right)\right]^{n}
$$

where $\mathrm{h}$ ', $\mathrm{h}$ - depth of generation and registration of the particle, respectively, $\mathrm{n}$ - number of interactions, $\mathrm{E}_{0-}$ the initial energy of the primary particle, $\sigma_{0}, a$,
$E_{0}, k-$ approximation coefficients, $\lambda_{0}=1 / \sigma_{0}$, $1=1 /\left(\lambda_{0}\right.$ ak $)$. Calculation of $\mathrm{CPF}$ is performed according to the formula:

$$
\begin{aligned}
\psi_{n}\left(h^{\prime}, h, E_{0}\right)= & \exp \left[-\ln (n !)-n^{*} \ln \left(\lambda_{0}\right)-\frac{1}{\lambda_{0} a k} \ln \left(\frac{E_{0}-k h^{\prime}}{E_{0}-k h}\right)+\frac{h-h^{\prime}}{\lambda_{0}}+\right. \\
& +n^{*} \ln \left(\frac{\ln \left(\frac{E_{0}-k h^{\prime}}{E_{0}-k h}\right)}{a k}-\left(h-h^{\prime}\right)\right],
\end{aligned}
$$

In order to calculate the KPF by formula (2), it is necessary to find coefficients of approximation $\sigma_{0}, a, E_{0}, k$ included in this expression. For this purpose, the interaction cross section is calculated by the Rutherford formula [12] there are depths of penetration from the tables of parameters of spatial distribution of ion-implanted impurities of Kumakhov-Komarov [13], the calculated section values are approximated with the following expression:

$$
\sigma(h)=\sigma_{0}\left(\frac{1}{a\left(E_{0}-k h\right)}-1\right)
$$

Then the approximation coefficients for the various ions in the aluminium have been found. Table 1 shows the approximation parameters for indium in aluminium. The results of the approximation selection are shown in figure 1 .

Table 1 - Approximation values for indium in aluminum

\begin{tabular}{|c|c|c|c|c|c|}
\hline $\mathrm{E}_{0}$ & $\sigma_{0} \times 10^{9}$ & $\alpha$ & $\mathrm{E}_{0}^{\prime}$ & $\mathrm{K}$ & $\eta$ \\
\hline 1000 & 165.94806 & 2.07165 & 0.00184 & 0.13615 & 0.99285 \\
\hline 800 & 176.93226 & 0.96197 & 0.00427 & 0.20159 & 0.99359 \\
\hline 500 & 226.59381 & 0.75709 & 0.00928 & 1.2488 & 0.99282 \\
\hline 200 & 290.18127 & 0.2588 & 0.03555 & 60.56595 & 0.99698 \\
\hline 100 & 408.7585 & 0.1165 & 0.10402 & 440.66742 & 0.99852 \\
\hline
\end{tabular}




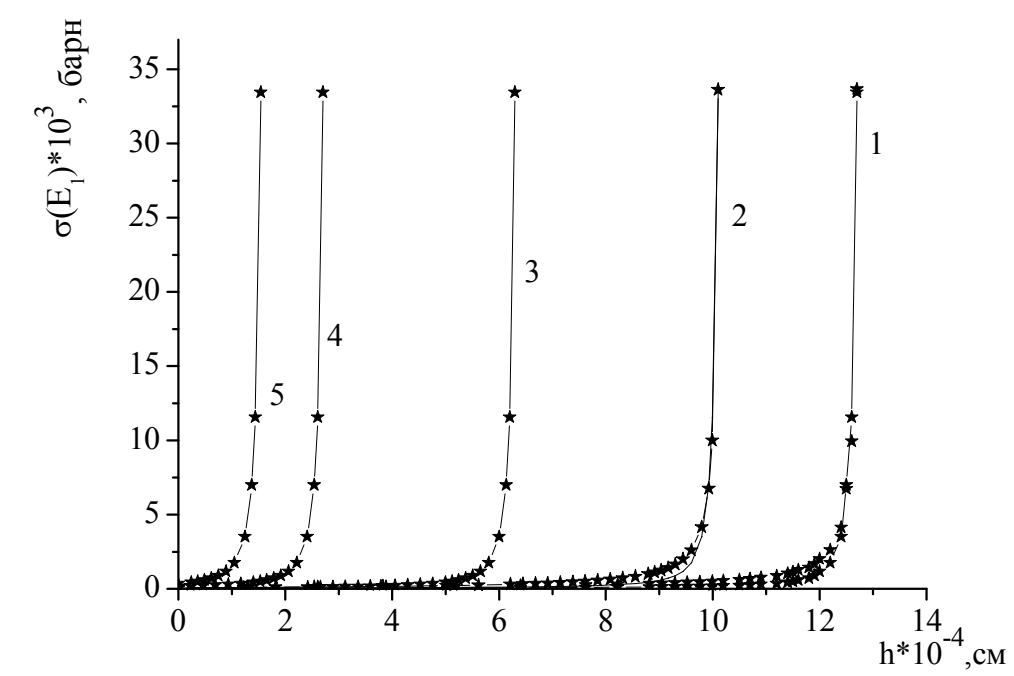

Figure 1 - Approximation of the modified section of the cascade-probability function for indium in aluminum $\mathrm{E}_{0}=1000(1), 800(2), 500(3), 200(4), 100(5) \mathrm{keV}$. Points - calculated data of the dependence of the cross section on depth, solid line - approximation

Further calculations of the CPF have been performed as a function of the number of interactions (Table 2) and the penetration depth of the particles (Table 3).

The regularities in the behavior of the result area and the step for calculation for the CPF, calculated as a function of the number of interactions during irradiation of aluminum by ions, are revealed.

1. At a small atomic weight of the incident particle and small depths, the maximum value of the CVF is reached approximately at $h / \lambda$. With increasing depth observation area of the result begins to shift in the area of small depths of the respective $h / \lambda$. and narrow.

2 . When the initial energy decreases (the particle and the target are the same) at the same depth the area of the result is also narrowed and shifted to the area of small depths.

3. As the atomic weight of the incident particle increases, the range of the result shifts to a region of shallow depths with respect to $h / \lambda$ and narrows.

4. At a large atomic weight of the incident particle, the maximum value of the CPF shifts to a region of shallow depths relative to $h / \lambda$ already at shallow depths, and at large depths the result is in a narrow region (less than $1 \%$, silver, gold).

5. The narrowest area of the result is obtained with a large atomic weight of the incident particle and a small target at the end of the run and reaches hundredths of a percent. At the same time the account is growing strongly.

Since $h / \lambda$ can be very large (tens of millions), then the values of the CPF, calculated in steps of 1 , will not practically differ from each other and the counting time will be very long (more than two hours). The step takes some value $N_{n}$, that is added to the current $\mathrm{n}$ and $\mathrm{KVF}$ is calculated at $n, n+N_{n}$, $n+2 N_{n} \quad \ldots$ Thus for calculating the CPF, it is necessary to find not only the area for determining the result, and also to choose a step. When choosing the step, the following regularities take place.

1. For a small atomic weight of the incident particle and small depths, the step is small (about 10-20), with increasing depth of observation it begins to increase.

2. With increasing atomic weight of the incident particle, the step accordingly increases, reaching several hundred and even thousands.

3. When the atomic weight of the flying particle increases, the step increases accordingly, reaching several hundred and even thousands.

4. The pitch greatly increases with a large atomic weight of the incident particle and a small target. 
Table 2 - Dependence of the percentage of displacement of the left and right boundaries of the result area on the number of interactions for nitrogen in aluminum: a) $\mathrm{E}_{0}=1000 \mathrm{keV}$; b) $\mathrm{E}_{0}=800 \mathrm{keV}$; c) $\mathrm{E}_{0}=500 \mathrm{keV}$; d) $\mathrm{E}_{0}=200 \mathrm{keV}$; e) $\mathrm{E}_{0}=100 \mathrm{keV}$

\begin{tabular}{|c|c|c|c|c|}
\hline$h^{*} 10^{4}, \mathrm{~cm}$ & $\mathrm{~B}_{1}, \%$ & $\mathrm{~B}_{2}, \%$ & $N_{n}$ & $\mathrm{~B}_{3}, \%$ \\
\hline 10 & 38 & 8 & 40 & 46 \\
\hline 15 & 39 & -8 & 35 & 3,1 \\
\hline 20 & 43,5 & -22 & 40 & 21,5 \\
\hline 25 & 49 & -33 & 45 & 16 \\
\hline 30 & 55 & -43 & 57 & 12 \\
\hline 35 & 62,4 & $-53,85$ & 65 & 8,55 \\
\hline 40 & 71,66 & $-66,6$ & 75 & 5,06 \\
\hline 45 & 84,88 & $-82,86$ & 95 & 2,06 \\
\hline
\end{tabular}

a)

\begin{tabular}{|c|c|c|c|c|}
\hline$h^{*} 10^{4}, \mathrm{~cm}$ & $\mathrm{~B}_{1}, \%$ & $\mathrm{~B}_{2}, \%$ & $N_{n}$ & $\mathrm{~B}_{3}, \%$ \\
\hline 10 & 37 & 1 & 35 & 38 \\
\hline 15 & 40,5 & -15 & 35 & 25,2 \\
\hline 20 & 46,5 & -28 & 47 & 18,5 \\
\hline 25 & 53,5 & $-40,7$ & 63 & 12,8 \\
\hline 30 & 62 & $-53,85$ & 75 & 8,15 \\
\hline 35 & 73,54 & $-68,9$ & 95 & 4,64 \\
\hline
\end{tabular}

b)

\begin{tabular}{|c|c|c|c|c|}
\hline$h^{*} 10^{4}, \mathrm{~cm}$ & $\mathrm{~B}_{1}, \%$ & $\mathrm{~B}_{2}, \%$ & $N_{n}$ & $\mathrm{~B}_{3}, \%$ \\
\hline 1 & 58 & 68 & 25 & 13 \\
\hline 4 & 35,3 & 20 & 30 & 55,3 \\
\hline 7 & 34 & 2 & 38 & 36 \\
\hline 10 & 37 & -11 & 48 & 26 \\
\hline 13 & 41,5 & $-22,23$ & 54 & 19,27 \\
\hline 16 & 47,5 & -33 & 67 & 14,5 \\
\hline 19 & 54,3 & $-44,4$ & 75 & 9,9 \\
\hline 22 & 62 & $-55,75$ & 97 & 6,25 \\
\hline 25 & 73,3 & -69 & & 44,3 \\
\hline
\end{tabular}

\begin{tabular}{|c|c|c|c|c|}
\hline$h^{*} 10^{4}, \mathrm{~cm}$ & $\mathrm{~B}_{1}, \%$ & $\mathrm{~B}_{2}, \%$ & $N_{n}$ & $\mathrm{~B}_{3}, \%$ \\
\hline 1 & 38,6 & 38 & 15 & 76,6 \\
\hline 3 & 30,2 & 6 & 24 & 36,2 \\
\hline 5 & 34 & -10 & 37 & 24 \\
\hline 7 & 40,5 & -24 & 45 & 16,5 \\
\hline 9 & 5 & $-39,8$ & 70 & 34,8 \\
\hline 11 & 62,23 & $-65,5$ & 85 & 3,27 \\
\hline 12 & 69,87 & $-65,3$ & & 4,57 \\
\hline
\end{tabular}

d)

\begin{tabular}{|c|c|c|c|c|}
\hline$h^{*} 10^{4}, \mathrm{~cm}$ & $\mathrm{~B}_{1}, \%$ & $\mathrm{~B}_{2}, \%$ & $N_{n}$ & $\mathrm{~B}_{3}, \%$ \\
\hline 1 & 30,5 & 21,5 & 25 & 52 \\
\hline 2 & 29,4 & 0,6 & 35 & 30 \\
\hline 3 & 33,8 & -12 & 43 & 21,8 \\
\hline 4 & 40,6 & -25 & 50 & 15,6 \\
\hline 5 & 49,2 & -39 & 60 & 10,2 \\
\hline 6 & 60,71 & -54 & 75 & 6,71 \\
\hline
\end{tabular}

e) 
Table 3 - Dependence of percentage of displacement of the left and right boundaries of the result area from the penetration depth for silver in aluminum: a) $\mathrm{E}_{0}=1000 \mathrm{keV}$; b) $\mathrm{E}_{0}=800 \mathrm{keV}$; c) $\mathrm{E}_{0}=500 \mathrm{keV}$; d) $\mathrm{E}_{0}=200 \mathrm{keV}$; e) $\mathrm{E}_{0}=100$ $\mathrm{keV}$

\begin{tabular}{|c|c|c|c|c|c|}
\hline$h^{*} 10^{4}, \mathrm{~cm}$ & $h / \lambda$ & $\mathrm{C}_{1}, \%$ & $\mathrm{C}_{2}, \%$ & $N_{h}$ & $\mathrm{C}_{3}, \%$ \\
\hline 1 & 13164 & $-1,37$ & 12 & 110 & 10,63 \\
\hline 3 & 52312 & $-15,4$ & 20,2 & 270 & 4,8 \\
\hline 5 & 119152 & $-25,3$ & 28,1 & 480 & 2,8 \\
7 & 241088 & $-31,192$ & 32,56 & 993 & 1,368 \\
\hline 9 & 499490 & $-30,415$ & 30,9 & 2800 & 0,485 \\
\hline
\end{tabular}

a)

\begin{tabular}{|c|c|c|c|c|c|}
\hline$h^{*} 10^{4}, \mathrm{~cm}$ & $h / \lambda$ & $\mathrm{C}_{1}, \%$ & $\mathrm{C}_{2}, \%$ & $N_{h}$ & $\mathrm{C}_{3}, \%$ \\
\hline 1 & 24110 & $-1,752$ & 9,5 & 150 & 7,748 \\
\hline 2 & 54588 & $-8,7$ & 14 & 240 & 5,3 \\
\hline 3 & 94062 & $-15,046$ & 18,8 & 360 & 3,754 \\
\hline 4 & 146836 & $-20,91$ & 23,5 & 480 & 2,59 \\
\hline 5 & 220484 & $-25,942$ & 27,8 & 780 & 1,858 \\
\hline 6 & 329673 & $-29,293$ & 30,45 & 1280 & 1,157 \\
\hline 7 & 507016 & $-29,507$ & 30,1 & 2480 & 0,593 \\
\hline 8 & 842620 & $-24,575$ & 24,745 & 8000 & 0,17 \\
\hline
\end{tabular}

b)

\begin{tabular}{|c|c|c|c|c|c|}
\hline$h^{*} 10^{4}, \mathrm{~cm}$ & $h / \lambda$ & $\mathrm{C}_{1}, \%$ & $\mathrm{C}_{2}, \%$ & $N_{h}$ & $\mathrm{C}_{3}, \%$ \\
\hline 1 & 42461 & $-6,52$ & 12,2 & 210 & 5,68 \\
\hline 2 & 106987 & $-17,073$ & 20,42 & 405 & 3,347 \\
\hline 3 & 213796 & $-25,93$ & 27,88 & 755 & 1,95 \\
\hline 4 & 418665 & $-30,226$ & 31.071 & 1800 & 0,845 \\
\hline 5 & 952474 & $-23,23$ & 23,342 & 11500 & 0,112 \\
\hline
\end{tabular}

c)

\begin{tabular}{|c|c|c|c|c|c|}
\hline$h^{*} 10^{5}, \mathrm{~cm}$ & $h / \lambda$ & $\mathrm{C}_{1}, \%$ & $\mathrm{C}_{2}, \%$ & $N_{h}$ & $\mathrm{C}_{3}, \%$ \\
\hline 1 & 9200 & 3,5 & 9,6 & 85 & 13,1 \\
\hline 4 & 43505 & $-7,57$ & 13,4 & 210 & 5,83 \\
\hline 7 & 91527 & $-15,84$ & 19,52 & 350 & 3,68 \\
\hline 10 & 160878 & $-22,93$ & 25,3 & 520 & 2,37 \\
\hline 13 & 266084 & $-28,37$ & 30 & 860 & 1,63 \\
\hline 16 & 438730 & $-30,934$ & 31,82 & 1650 & 0,886 \\
\hline 19 & 762930 & $-28,45$ & 28,78 & 4600 & 0,33 \\
\hline
\end{tabular}

d)

\begin{tabular}{|c|c|c|c|c|c|}
\hline$h^{*} 10^{5}, \mathrm{~cm}$ & $h / \lambda$ & $\mathrm{C}_{1}, \%$ & $\mathrm{C}_{2}, \%$ & $N_{h}$ & $\mathrm{C}_{3}, \%$ \\
\hline 1 & 20130 & $-0,6$ & 9,5 & 133 & 8,9 \\
\hline 3 & 74350 & $-11,82$ & 16 & 305 & 4,24 \\
\hline 5 & 156710 & $-20,79$ & 23,5 & 525 & 2,71 \\
\hline 7 & 288940 & $-27,77$ & 29,5 & 900 & 1,73 \\
\hline 9 & 522905 & $-31,107$ & 31,86 & 1900 & 0,753 \\
\hline 11 & 1020546 & $-27,316$ & 27,54 & 6600 & 0,224 \\
\hline
\end{tabular}

e) 
Some regularities appearing when finding the real domain of determination for the $\mathrm{CPF}$, calculated depending on the penetration depth, are noted.

1. Calculations show that for a small atomic weight of the incident particle and small depths, the region of the result of the CPF as a function of $h$ is near $h$, which corresponds to $h / \lambda$. When the depth of observation is increased, the result area shifts to a region of greater depths and narrows.

2. When the initial energy of the particle decreases (the incident particle is the same) at the same depth of observation, the resultant region shifts to a region of large depths and narrows.

3 . When the depth of observation is increased for any incident particle, the result area shifts to the right.

4. Depending on the atomic number of the incident particle at the same value of the depth $h$, the result area shifts to a region of large depths.

5 . When a large value of the atomic number of the projectile is the area of the result is shifted to larger depths relative to $h$ corresponding to $h / \lambda$ already at shallow depths.

To calculate CPF in the found area, you must specify a step. In this case, a certain $N_{h}$ value was taken as a step, which was added to the current $h$ and the CPF was calculated at $\mathrm{h}, h+N_{h}, h+2 N_{h}, \ldots$ Let's note some regularities of behavior of a step.

1. For a small atomic weight of the flying particle the step is small, with increase in depth of observation it increases, and on the end of a run very strongly.

2. With decrease of tentative energy of a particle with the same depth of observation (the flying particle same) the step also increases.

3. With increasing atomic weight of the incident particle for one and the same depth of observation, the step increases first gradually, then very sharply.

Next, calculations of the concentration of radiation defects for various incident particles in aluminum have been made using the following formula:

$$
C_{k}\left(E_{0}, h\right)=\int_{E_{c}}^{E_{2 \max }} W\left(E_{0}, E_{2}, h\right) d E_{2},
$$

$E_{2}$ - primary knocked-out energy, $\mathrm{E}_{2 \max }$ the maximum kinetic energy that the atom will receive, $E_{c}$ - threshold energy, $W\left(E_{0}, E_{2}, h\right)$ - the spectrum of primary knocked-out atoms. The results of the calculations are presented in Tables 4-6.

Table 4 - Limits of the region of determination of the concentration of radiation defects for germanium in aluminum at $\mathrm{E}_{\mathrm{c}}=50 \mathrm{keV}, \mathrm{E}_{0}=1000 \mathrm{keV}$

\begin{tabular}{|c|c|c|c|c|c|}
\hline $\mathrm{h}^{*} 10^{-4}, \mathrm{~cm}$ & $\mathrm{C}_{\mathrm{K}}, \mathrm{cm}$ & $\mathrm{E}_{0}, \mathrm{keV}$ & $\mathrm{n}_{0}$ & $\mathrm{n}_{1}$ & \multicolumn{1}{c|}{$5^{\prime \prime} 75$} \\
\hline 0,1 & 31452,9 & 1000 & 342 & 663 & $1^{\prime} 26^{\prime \prime}$ \\
\hline 2 & 34640,8 & 900 & 10319 & 2472 & $4^{\prime} 10^{\prime \prime}$ \\
\hline 4 & 38790,1 & 800 & 22509 & 3928 & $7^{\prime} 25^{\prime \prime}$ \\
\hline 6 & 44060,6 & 700 & 36526 & 57102 & $12^{\prime} 57$ \\
\hline 8,1 & 51426,5 & 600 & 53795 & 77333 & $19^{\prime} 32^{\prime \prime}$ \\
\hline 10,1 & 61077,3 & 500 & 73611 & 101215 & $29^{\prime} 03^{\prime \prime}$ \\
\hline 12 & 74085,3 & 400 & 96941 & 116424 & $36^{\prime} 55^{\prime \prime}$ \\
\hline 13 & 83450 & 350 & 111802 & 134213 & $44^{\prime} 33$ \\
\hline 14 & 95400,5 & 300 & 129231 & 140152 & $47^{\prime} 20$ \\
\hline 14,3 & 99134,5 & 280 & 135104 & 148774 & $53^{\prime} 42^{\prime \prime}$ \\
\hline 14,7 & 105238 & 260 & 143505 & 158192 & $59^{\prime}$ \\
\hline 15,1 & 112049 & 240 & 152665 & 168361 & $1^{0} 03^{\prime}$ \\
\hline 15,5 & 119653 & 220 & 162734 & 176816 & $1^{0} 09^{\prime}$ \\
\hline 15,8 & 124508 & 200 & 171000 & 189101 & $1^{0} 14^{\prime}$ \\
\hline 16,2 & 133078 & 180 & 183184 & 203203 & $1^{0} 23^{\prime}$ \\
\hline 16,6 & 142065 & 160 & 197029 & 215170 & $1^{0} 30^{\prime}$ \\
\hline 16,9 & 144496 & 140 & 208809 & 233671 & $1^{0} 44^{\prime}$ \\
\hline 17,3 & 148840 & 120 & 226991 & 250085 & $1^{0} 55^{\prime}$ \\
\hline 17,6 & 135244 & 100 & 243135 & 277085 & $2^{0} 17^{\prime}$ \\
\hline 18 & 99265,8 & 80 & 269617 & 302961 & $2^{0} 22^{\prime}$ \\
\hline 18,1 & 48551,7 & 70 & 295266 & & $2^{0} 33^{\prime}$ \\
\hline 18,3 & 0 & 60 & & & \\
\hline
\end{tabular}


Table 5 - Limits of the region of determination of the concentration of radiation defects for germanium in aluminum at $\mathrm{E}_{\mathrm{c}}=50 \mathrm{keV}, \mathrm{E}_{0}=500 \mathrm{keV}$

\begin{tabular}{|c|c|c|c|c|}
\hline $\mathrm{h}^{*} 10^{4}, \mathrm{sm}$ & $\mathrm{C}_{\mathrm{K}}, \mathrm{cm}^{-1}$ & $\mathrm{E}_{0}, \mathrm{keV}$ & $\mathrm{n}_{0}$ & 732 \\
\hline 0,1 & 55205,65 & 500 & 21344 & $\mathrm{n}_{1}$ \\
\hline 2 & 68422,14 & 400 & 34982 & 23380 \\
\hline 3 & 77960,77 & 350 & 49461 & 57597 \\
\hline 3,9 & 88414,43 & 300 & 56753 & 60141 \\
\hline 4,3 & 94041,72 & 280 & 64696 & 68332 \\
\hline 4,7 & 100325,61 & 260 & 71149 & 74955 \\
\hline 5 & 104745,65 & 240 & 80531 & 84510 \\
\hline 5,4 & 112163,36 & 220 & 90980 & 95309 \\
\hline 5,8 & 120392,95 & 200 & 99669 & 105065 \\
\hline 6,1 & 125325,64 & 180 & 112668 & 117351 \\
\hline 6,5 & 133914,22 & 160 & 127742 & 132743 \\
\hline 6,9 & 142074,07 & 140 & 140849 & 146091 \\
\hline 7,2 & 140336,23 & 120 & 161665 & 167314 \\
\hline 7,6 & 134940,54 & 100 & 180855 & 186858 \\
\hline 7,9 & 92994,21 & 80 & 196123 & 202371 \\
\hline 8,1 & 49191,1 & 70 & 204751 & 211247 \\
\hline
\end{tabular}

Table 6 - Limits of the region of determination of the concentration of radiation defects for germanium in aluminum at $\mathrm{E}_{\mathrm{c}}=50 \mathrm{keV}, \mathrm{E}_{0}=200 \mathrm{keV}$

\begin{tabular}{|c|c|c|c|c|}
\hline $\mathrm{h} * 10^{4}, \mathrm{~cm}$ & $\mathrm{C}_{\mathrm{K}}, \mathrm{cm}$ & $\mathrm{E}_{0}, \mathrm{keV}$ & $\mathrm{n}_{0}$ & $\mathrm{n}_{1}$ \\
\hline 0,1 & 123843,73 & 200 & 2374 & 11019 \\
\hline 0,4 & 130916,49 & 180 & 20901 & 12529 \\
\hline 0,7 & 137135,12 & 160 & 36251 & 22972 \\
\hline 1,1 & 147583,01 & 140 & 49806 & 38951 \\
\hline 1,4 & 147032,15 & 120 & 71572 & 53019 \\
\hline 1,8 & 142423,51 & 100 & 91756 & 75422 \\
\hline 2,1 & 98253,23 & 80 & 107808 & 96218 \\
\hline 2,3 & 51800,91 & 70 & 126727 & 112501 \\
\hline 2,5 & 0 & 60 & & 131688 \\
\hline
\end{tabular}

Finding the region of the result of the concentration of radiation defects during ion irradiation made it possible to reveal the following regularities:

1. During the reduction of the initial energy of the primary particle, the range of the result area shifts to a region of greater depths, the values of the concentration of radiation defects increase.

2. Counting time and reaches several hours increases greatly with a large atomic weight of the flying particle and a small target.

3. Depending on the penetration depth, the initial and final values of the number of interactions increase, the interval of the result area $\left(\left(n_{0} n_{1}\right)\right.$ also increases and shifts to the greater depths.

4. The interval of the result area is significantly shifted to the right and increases, the value of the concentration at the maximum point and the concentration values themselves greatly increase with the atomic number of the incident particle.

\section{Conclusion}

Thus, the paper presents a mathematical model of a cascade-probability function with allowance for energy losses for ions, an algorithm for calculating $\mathrm{CPF}$, an approximation of the interaction cross section, and approximation coefficients for indium in aluminum. Calculations of $\mathrm{CPF}$ for various incident particles in aluminum are performed, depending on the number of interactions and the penetration depth of the particles. The regularities in the behavior of the area of the CPF result and the step for calculation are revealed. A model for 
calculating the concentration of radiation defects is presented, calculations are performed, regularities in the behavior of the result area are obtained depending on various factors.

\section{References}

1. Agranovich B.M., Kirsanov B.B. "Problemy modelirovaniya radiatsionnogo povrezhdeniya $\mathrm{V}$ kristallakh" ("Problems of Modeling Radiation Damage in Crystals"). Successes of physical sciences 1 (1976): 2-51. (in Russian).

2. "Modelirovanie na EHVM defektov $v$ kristallah." ("Computer simulation of defects in crystals"). In Materials of the All-Union Seminars, ed. by Orlov A.N., Trushina Yu.V. Leningrad: FTI named after AI. Ioffe AS of the USSR Publ., 1979. -205 p. (in Russian).

3. Akkerman A.F., Nikitushev Yu.M., Botvin V.A. Resheniye metodom Monte-Karlo zadach perenosa bystrykh elektronov $v$ veshchestve. (Solution by the Monte Carlo method of problems of transfer of fast electrons in matter). Alma-Ata: Nauka Publ., 1972. - 162 p. (in Russian).

4. Caro A. "Molecular dynamic approach to heavy ion impast." Radiation Effects and Defects in Solids 126 (1993): 15-20.

5. Zou Y., Waya Y.A., Kambara T., Kanai Y., Oivra M. Ardo K., Hitashi A., Kravis S. "Foil target element and incident energy dependence of multiple inner shell vacancy production of projectile ar ions." Radiation Effects and Defects in Solids 126 (1993): 87-90.

6. Audouard A., Balanzar E., Jousset J.C., Lesueur D., Thome L. "Anisotropy of the atomic movements induced in amorphous metallic alloys by swift heavy ion irradiation." Radiation Effects and Defects in Solids 126 (1993): 93-96.

7. Fink D., Chadderton L.T., Cruz S.A., Fahrner W.R. Hnatowir V., E.H. te Kaat, Melnikov A.A., Varichenko V.S., Zaitsev A.M. "Ion Tracks in condensed carbonaceus matter." Radiation Effects and Defects in Solids 126 (1993): 247-250.

8. Bjeoumikhov A., Buzanich G., Langhoff N., Soltau H., (...), Wedell R. "The SLcam: A full-field energy dispersive X-ray camera." Journal of Instrumentation 7, no. 5 (2012): 248-252.

9. Bock M., Skibina J., Fischer D., (...), Beloglazov V., Steinmeyer G. "Nanostructured fibers for sub-10 fs optical pulse delivery." Laser and Photonics Reviews 7, no. 3 (2013): 566-570.
10. Dubovichenko S., Burtebayev N., Dzhazairov-Kakhramanov A., (...), Kliczewski S., Sadykov T. "New measurements and phase shift analysis of p160 elastic scattering at astrophysical energies." Chinese Physics C 41, no. 1 (2017): 485495.

11. Conopleva R.F., Litvinov V.L., Uhin N.A. Osobennosti radiatsionnogo povrezhdeniya poluprovodnikov vysokoenergeticheskimi chastitsami. (Features of radiation damage to semiconductors by high-energy particles). Moscow: Atomizdat Publ., 1971. - 175 p. (in Russian).

12. Boss E.G., Kupchishin A.I. Solution of physical tasks by a cascade and probabilistic method. Alma-Ata: Science, 1988. - 112 p.

13. Boss E.G., Kupchishin A.I. Solution of physical tasks by a cascade and probabilistic method. Alma-Ata: Science 1, 1998. - 144 p.

14. Boos E.G., Kupchishin A.A., Kupchishin A.I., Shmygalev E.V., Shmygaleva T.A. Cascade and probabilistic method, solution of radiation and physical tasks, Boltzmann's equations. Communication with Markov's chains. Monograph. Almaty: KazNPU after Abay, Scientific Research Institute for New Chemical Technologies and Materials under al-Farabi KazNU. 2015. - $388 \mathrm{p}$.

15. Merkle K.L. Radiation-induced point defects clusters in copper and gold." Physica status solidi 18, no. 1 (1966): 173-188.

16. Burenkov A.F., Komarov F.F., Kumakhov M.A., Temkin M.M. Tables of parameters of the spatial distribution of ion implanted impurities. Minsk: BSU named after Lenin Publ., 1980. $-352 \mathrm{p}$.

17. Czarnacka, K., Komarov, F.F., Romanov, I.A., Zukowski, P., Parkhomenko, I.N. "AC measurements and dielectric properties of nitrogenrich silicon nitride thin films." Proceedings of the 2017 IEEE 7th International Conference on Nanomaterials: Applications and Properties, NAP 2017, no. 5 (2017): 657-669.

18. Komarov, F.F., Milchanin, O.V., Parfimovich, I.D., Tkachev, A.G., Bychanok, D.S. "Absorption and Reflectance Spectra of Microwave Radiation by an Epoxy Resin Composite with Multi-Walled Carbon Nanotubes." Journal of Applied Spectroscopy 84, no. 4 (2017): 570-577.

19. Komarov F.F. "Nano- and microstructuring of solids by swift heavy ions." Physics-Uspekhi 187, no. 5 (2017): 465-504 